\title{
Family Caregiving Supports
}

D. L. Wagner and G. G. Hunt. The use of workplace eldercare programmes by employed caregivers. Research on Aging, 16, I (1994), 69-83.

Family caregiving by sons, daughters, husbands, wives and other family members has become a dominant gerontological theme in many countries of the world. Numerous research studies describe the stresses to individual caregivers in the physical, psychosocial spheres as they assume the roles of caregiving, manage separate homes and family, and maintain a career. Eldercare programmes for family caregivers in the workplace have become a quite common benefit provided by American employers, so much so that they are described as the 'benefit of the nineties', but many questions regarding their effectiveness and use remain unanswered. This paper, a pilot cross-sectional study, examines the correlates of employees' use of workplace eldercare programmes and the reasons why some family caregiver employees use the programme and others do not. The research questions included:

I. Was lack of knowledge of the programme a significant barrier to use?

2. Did users and nonusers differ by the type of caregiving situation?

3. Did users and nonusers differ in attitudes about work-family issues?

4. Did users and nonusers differ in the degree to which they were experiencing work-related problems as a consequence of their caregiving activities?

Two companies who use the same vendor to offer work-site eldercare programmes are examined in this study. Their programmes consisted of work-site fairs, free telephone number for information, counselling and referral to local resources, seminars and workshops about caregiving issues, a newsletter, and support groups. The companies were large, employing 55,000 and 3,000 persons respectively, but the use of the programmes was only i $\%$ for one and $4 \%$ for the other. The study sample of I I 5 persons was secured from employee lists of nonusers and from the sub-sample of users randomly selected from client lists. The average age of the sample was 40.4 years, $67 \%$ were female, and $78 \%$ were the primary caregivers of a parent. Users had provided care for an average of 4.3 years and currently averaged I I .2 hours per week, while nonusers had cared for 7.2 years and currently cared for 10.7 hours per week.

Both users and non-users of the eldercare programme were assessed by using structured interviews over the telephone, plus personal interviews 
either at the home or work site. Caregiving was defined as giving both instrumental assistance and emotional support for an older person. A primary caregiver was defined as the individual within the kinship or social support group who would most likely be called upon to make decisions for the older person if unable to do so for him or herself.

For non-users of the programme, $80 \%$ knew of it but chose not to use it. When comparing the caregiving activities of users and non-users, significant differences were found in three caregiving activities: (I) non-users had higher rates in helping with shopping, (2) users participated more in managing the care of the older person, such as arranging for services, and (3) users helped more than non-users with insurance paper work and financial matters. Users were most often also primary caregivers and assumed responsibility for a relative who lived at a distance.

In analyzing attitudes about work-family programmes, attitudes did not seem to deter their use, since $90 \%$ of the respondents indicated the programme was a good one and that they would use it if they needed a service. Non-users stated they were somewhat uncomfortable discussing their caregiving at work and that they refrained from talking about it with their supervisors or co-workers. Non-user caregivers more than users indicated that they experienced minimal or no interference with their work and had minimal or no missed days of work because of their caregiving.

It is concluded that interference with work and the attitudes of employers are significant factors in deciding to use an eldercare programme. The role of managing care of the older person was positively associated with using the programme. However, 'hands-on' caregiving was negatively associated with its use.

L. B. Gerald. Paid family caregiving: a review of progress and polices. Journal of Aging and Social Policy, 5, I/2 (1993), 73-89.

A phenomenal increase in life expectancy has occurred in the United States of America (USA) since 1900. During 1946-1964, 76 million Americans were born in the 'baby boom'. The 'oldest old' group, those aged 85 years and over, will double from i 980 to the year 2000. They will need more medical and non-medical help including institutionalization than any other age group. Estimates indicate however that $16-35 \%$ would not require institutionalization if they had support from the family and community. Large numbers of elderly people (about $80 \%$ ) receive care from family members, most of who are spouses and adult children particularly women. The average 
woman spends $\mathrm{I} 8$ years being a caregiver for an older parent and $\mathrm{I} 7$ years caring for dependent children. They undertake the multiple roles of wife, mother and caregiver. About $73 \%$ are also employed outside the home. Furthermore, the cost of nursing home care has become prohibitive and extended nursing home care is not covered by Medicare.

Overall, research indicates the burden of caregiving affects the quality of life for both the caregiver and the older adult. The role of family caregiver impacts upon the personal life of the caregiver by decreasing the time for vacation, socialization and care of the home. In addition, the role of caregiving is financially and emotionally draining, and may adversely affect the caregivers' job performance. It may also influence the number of elderly people admitted to nursing homes and increase the incidence of elder abuse.

The history of paid caregiving in the USA shows that generally there has been minimal financial support for long term caregiving by the family. More research is needed because paid family caregiving issues are complex and require the perspectives of family caregivers, older adults and social service providers. Sweden may have the most comprehensive support programme in the world for family caregivers. An insurance allowance for a 30 day period once in a lifetime to care for an older person is available. Caregivers' relatives are salaried for providing at least 20 hours per week of care to elderly people. There are over I 0,000 such salaried caregivers in Sweden. Respite services further support family caregivers to help reduce their stress. When the need for caregiving is over, labour market training is offered to caregivers.

In the United Kingdom (UK), the Invalid Care Allowance (ICA) offers a regular allowance for caregiving to an older or disabled person who is entitled to an Attendance Allowance (AA). All qualified disabled persons have a right to AA irregardless or their income. They receive the allowance directly and may or may not use it to purchase care. In cases where the care receiver does not receive the allowance, the caregiver may separately apply for ICA. Several other restrictions however limit the use of the ICA, e.g. the caregiver must be of preretirement age to receive it, only then can they receive ICA after retirement. When caregivers receive a pension they cannot qualify for ICA and vice versa, and individuals who work are ineligible for ICA. Overall, the UK system is very restrictive when compared to the Swedish model.

Policymakers in the USA have considered various options to promote and share caregiving between families and the government. Relatives of those receiving Medicaid currently do not receive 
compensation for caregiving. The benefits of older adults on Supplementary Security Income (SSI) and Medicaid are even reduced if family members support them with money, or if they receive lodging, food and clothing from individuals. On the other hand, institutionalized older adults can receive Medicaid. As those living at home may be ineligible for these funds, this may promote early institutionalization.

A few States utilizing the Medicaid 'Home and Community Based Care Waivers' offer financial allowances to family caregivers through Medicaid. They believe this offers the older adult a choice of caregiver and that it is more cost effective. The care is thought to be more personal and to fill gaps when professional caregivers are not present. Such compensation for caregivers is thought to increase their motivation to remain as family caregivers. Tax incentives for caregivers have also been considered. Currently taxpayers may claim an elderly dependent person as a dependant if that individual's annual income is below $\$ 1000$ and the caregiver provides over half the support for the individual. Obviously, limited numbers of caregivers can qualify for this option. Other incentives include deductions from taxable income and tax credits which are applied directly against the taxpayer's liability which could allow for some caregiver compensation. Expansion of the 'Temporary Disability Insurance' (TDI) model is proposed by Wisensale ( $199 \mathrm{I}$ ) to include caring for individual family members of any age by offering them adequate wage replacement. A few States provide leave to care for an older parent, but none as yet allow for wage replacement. Twenty States allow for some type of direct payment for caregiving; however, it varies from State to State.

Minimal research has investigated if financial allowances are an effective approach in supporting family caregivers. It indicates that the financial burden is less troublesome than the emotional and physical strain caregivers experience. This does not however suggest financial concerns are not burdensome. Overall the data supports a combination of both financial and support services for caregivers as most effective.

\section{COMMENT}

As life-expectancy increases the number of elderly people with disabilities and care needs also increases. The impact on families, society and government will escalate as the multiple diverse needs of dependants and their children become dominant in the family system. The first article investigates one method of dealing with the burden of caregiving, namely the use of workplace eldercare programmes. While this is a pilot study, it suggests that employee use of such programmes 
is correlated with the type of caregiving situation and with the workrelated burdens which accompany caregiving. Because of the small sample this study is not generalizable to the population as a whole. It can, however, stimulate further research focusing on caregiver burden and the utilization of eldercare employee programmes. A closer study of older adults' personal characteristics, their health status, level of selfsufficiency and dependency, coping skills, and the community resources available to them, would further define the needs. Additionally, a description of caregivers' individual characteristics, health status, work and other responsibilities, and how they deal customarily with family issues as they relate to caregiver needs, may assist in developing family caregiver support systems. Available eldercare workplace programmes might also be investigated as to services offered, those most utilized, employee satisfaction with them, and the impact on the work role.

Linked to the family caregiving role are the financial needs of the caregiver. The reviewed article presents a comprehensive look at the past, present and future needs for paid caregiving. It begins by discussing the growing numbers of elderly people who need care and the dramatic effect current trends may have on the family, especially women. Then it examines the history of paid caregiving in the United States, cross-cultural perspectives and proposals to support family caregiving.

There is much to discuss and much policy development to undertake. A half-century ago families were more intact, while today over half are single parent or blended nuclear families. In many, both spouses are employed, large numbers below the poverty level. As the cost in institutional care escalates, concerted efforts need to be made to provide less costly and more personal family care in which the older adult can remain an integral member. This cannot be accomplished without a public-private alliance that offers support systems and financial support. While instituting such a plan will be costly, it offers the potential of promoting family cohesion and support plus a financial reprieve for a health care system.

\section{Reference}

Wisensale, S. K. I991. An intergenerational policy proposal for the Ig9os: applying the temporary disability insurance model to family caregiving. Journal of Aging and Social Policy, $3(1 / 2),{ }_{1} 63-183$.

St Petersburgh Junior College, Florida 